"The final publication is available at http://dx.doi.org/ 10.1016/j.ijer.2016.06.003." International Journal of Educational Research. 2016, 79: 86-96. Students' experiences of the development of emotional engagement. Authors: Sanna Ulmanen, Tiina Soini, Janne Pietarinen \& Kirsi Pyhältö.

\title{
Students' experiences of the development of emotional engagement
}

[The Institument has been downloaded from TamPub.uta.fi Keywords: emotional engagement, sense of belonging, teacher-student relationships, peer relationships

\begin{abstract}
The stability and internal dynamics of students' emotional engagement was examined in a longitudinal study among primary and secondary school students over three terms. A total of 170 students were surveyed, and the study was conducted using structural equation modelling. The results showed that emotional engagement remained stable over time. Furthermore, the results showed that the students' emotional engagement in teacher-student relationships associated with emotional engagement in peer relations and explained the perceived peer-group relations over time. Surprisingly, the association between teacher-student and peer-group relations was stronger among the secondary school students than among the primary school students, implying that despite the contextual differences, teachers have real opportunities to promote positive peer influences at different phases of the school path.
\end{abstract}

\section{Introduction}

For a successful educational trajectory, it is crucial that students engage in schoolwork emotionally so that they feel they belong to the school community, both in teacher-student and peer relationships, and have positive affects towards school work in general (Appleton, Christenson, \& Furlong, 2008). Emotional engagement has been found to be related to positive future orientations (Crespo, Jose, Kielpikowski, \& Pryor, 2013; Israelashvili, 1997) and overall development in adolescence (Debnam, Johnson, Waasdorp, \& Bradshaw, 2014). Engaging in teacher and peer relationships helps students to learn empathy and negotiation skills, and enhances their sense of self-worth and experienced well-being (Bagwell, Newcomb, \& Bukowski, 1998; Wentzel, 1998). Moreover, a sense of belonging has been associated with employing effort, attention, and persistence in initiating and sustaining learning activities (Furrer \& Skinner, 2003; Li, Lerner, \& Lerner, 2010; Li \& Lerner, 2013) and displaying deep processing 
in learning (Dupont, Galand, Nils, \& Hospel, 2014). It has also been suggested to be an ingredient in the enjoyment of learning (Ulmanen et al. submitted). In turn, a lack of social support and (peer) rejection impairs students' school performances and increases the risk of loneliness and long-term emotional and behavioural difficulties (Gest, Graham-Bermann, \& Hartup, 2001; Harel-Fisch et al., 2011; Ladd, 1999).

Prior research within the area has focused heavily on the relationship between emotional engagement and school achievement. However, the internal dynamics of emotional engagement, particularly in terms of social interactions within school, have been less studied. In particular, knowledge on how teacher-student relationships contribute to peer relations and how teachers can promote students' emotional engagement in peer-group relations in the school context is still scarce. Although teacher-student relationships that are characterized by warmth, empathy, and support are shown to promote peer acceptance (Gest \& Rodkin, 2011; Hughes \& Chen, 2011) and prosocial behaviour (Luckner \& Pianta, 2011), and reduce peer rejection among middle-school students (Gazelle, 2006), as far as we are aware, there are no previous longitudinal studies exploring how the student's sense of belonging in peer and teacher-student relationships are interrelated and evolve over time.

This study focuses on exploring the development of students' emotional engagement in terms of teacherstudent and peer-group relations over three academic terms. Both the stability of students' emotional engagement in teacher-student and peer relationships and the development of the interrelation over time is tested (from grades five to six and from grades seven to eight). In addition, differences between primary and secondary school students are explored.

\subsection{A sense of belonging as a constituent of emotional engagement}

Emotional engagement is a part of school engagement; it also consists of behavioral and cognitive dimensions (Fredricks, Blumenfeld, \& Paris, 2004). Behavioural engagement entails active participation and involvement in studying and learning, whereas cognitive engagement refers to the student's personal investment in learning activities, including self-regulation and a commitment to the mastery of learning 
(Fredricks et al., 2004). Furthermore, emotional engagement comprises of experiences of belonging within the school community, including experienced relationships with teachers and peers and the affective dimensions of learning and emotions towards school in general (Eccles et al., 1993; Fredricks et al., 2004). Although the emotional, behavioural, and cognitive components of academic engagement are often explored separately, they mutually influence each other over time. It has been suggested that emotional engagement plays a significant and distinct role in the ways in which students engage in academic activities as their school career progresses (Li \& Lerner, 2013). In addition, behavioural engagement has received the most attention in prior studies, whereas emotional engagement has been studied less (Fredricks et al., 2004; Sagayadevan \& Jeyaraj, 2012).

Prior studies on emotional engagement have focused heavily on students' emotional reactions towards the school environment (Gonida, Voulala, \& Kiosseoglou, 2009; Wellborn \& Connell, 1987) and students’ valuing of schoolwork (Elffers, Oort, \& Karsten, 2012; Wang, Willett, \& Eccles, 2011). Emotional engagement has been typically perceived as a mediator between teacher-student relations and academic outcomes (Sagayadevan \& Jeyaraj, 2012), and hence explored either as a predictor of school achievement and overall school engagement or as an outcome in itself (Sagayadevan \& Jeyaraj, 2012). In addition, external factors, such as parental socio-economic status contributing to the students' valuing of schoolwork and emotional reactions towards schoolwork, have been extensively studied (Elffers et al., 2012; Gonida et al., 2009; Lee, 2012). However, the social dimensions of emotional engagement and their interrelations have been less often the focus of studies (Elffers et al., 2012; Lee, 2012; Li \& Lerner, 2013; Sagayadevan \& Jeyaraj, 2012).

The social ingredients of student emotional engagement consist of the student's sense of belonging in peer and student-teacher relationships, which relate the student to the particular social context of the school (Finn, 1989; Goodenow, 1993). The sense of belonging in school refers to the extent to which the student feels personally accepted, respected, and supported both by the teachers and his/her peers (Goodenow, 1993). Although a sense of belonging both in student-teacher and peer relationships is a central determinant of a student's emotional engagement, the relationships can play different functions. 
An extensive body of research shows that students who consider their teacher to be caring and accepting are likely to internalize the academic and prosocial goals valued by their teacher (Wentzel, 1999). This further improves their engagement in academic activities (A. R. Anderson, Christenson, Sinclair, \& Lehr, 2004; Furrer \& Skinner, 2003; Klem \& Connell, 2004; Lee, 2012; Patrick, Ryan, \& Kaplan, 2007; Roeser, Midgley, \& Urdan, 1996). At the same time, close relationships with peers have been shown to support students’ positive emotions towards schoolwork (Furrer \& Skinner, 2003). However, study burnout (Kiuru, Aunola, Nurmi, Leskinen, \& Salmela-Aro, 2008), negative behaviour, and negative school-related beliefs have been found to flourish in close relationships (Berndt, Hawkins, \& Jiao, 1999; Hallinan \& Williams, 1990; Sage \& Kindermann, 1999). In fact, it has been found that students neglected by their peers are the most motivated to learn (Wentzel \& Asher, 1995).

\subsection{The influence of teachers on peer relations}

There is substantial evidence that engagement in school is likely to be fostered in a caring and supportive learning environment (Battistich \& Solomon, 1997; Battistich, Solomon, Watson, \& Schaps, 1997). Teachers play a key role in fostering the students' sense of belonging (Roeser et al., 1996) and hence in their emotional engagement. Teachers' emotional support - including the teachers’ sensitivity, interest in the students' development, ability to understand the students' perspectives, and respectful and fair treatment of students - has been found to promote students' sense of belonging in teacher-student relationships (Hoffman, Richmond, Morrow, \& Kandice, 2002; Lee, 2012; Pakarinen et al., 2010; Roeser et al., 1996). In particular, for students at risk, continuous teacher support has been found to reduce the risk of school drop-out and decrease the display of antisocial behaviour (Spilt, Hughes, Wu, \& Kwok, 2012). In turn, a lack of close relationships with teachers has been shown to increase the risk of academic and behavioural problems (Anderman \& Anderman, 1999).

Peers also play central role in creating a climate of emotional support for students. The peer groups and crowds provide students with a sense of emotional security (Brown, Eicher, \& Petrie, 1986). However, the behaviour of teachers has also been shown to have substantial impact on promoting positive peer influences and constructing an emotionally secure learning environment in a peer context (Gest \& 
Rodkin, 2011; Hughes \& Chen, 2011; Luckner \& Pianta, 2011). For example, a teacher’s effort to promote mutual respect among classmates was shown to improve the sense of belonging among middle-school students (Anderman, 2003). Teacher-student relationships characterized by warmth, empathy and support have been found to promote peer acceptance (Gest \& Rodkin, 2011; Howes \& Hamilton, 1994; Hughes \& Chen, 2011) and pro-social behaviour (Birch \& Ladd, 1998; Luckner \& Pianta, 2011), and to reduce peer rejection (Gazelle, 2006) and rates of aggression (Howes \& Hamilton, 1994; Luckner \& Pianta, 2011). In turn, conflicts in student-teacher relationships have been associated with asocial and antisocial student behaviour, such as aggression towards and the avoidance of peers (Birch \& Ladd, 1998). By promoting a strong sense of belonging in teacher-student relationships, teachers can directly promote positive peer behaviour. This allows students to take academic, social, and emotional risks, and to learn from them (Birch \& Ladd, 1998; Hamre \& Pianta, 2001; Luckner \& Pianta, 2011). Teachers provide a model of accepted social behaviours in the classroom and create an environment for practising and learning social skills. This means that the competencies, expectations, and attitudes developed within teacher-student relationships also influence peer relationships (Birch \& Ladd, 1998; Hamre \& Pianta, 2001; Howes \& Hamilton, 1994; Luckner \& Pianta, 2011).

The way in which the teacher manages time and the students' behaviour (i.e. classroom organization) provides or denies opportunities for students to work with peers (Pakarinen et al., 2010) and influences the students' social network, skills, and quality of relationships (Downer, Booren, Lima, Luckner, \& Pianta, 2010; Luckner \& Pianta, 2011). Well-managed classrooms, where students have a plenty of opportunities to develop their self-regulatory skills and practise positive peer interactions (Cameron, Connor, \& Morrison, 2005; Zimmer-Gembeck \& Locke, 2007), have been associated with a strong sense of belonging (Luckner \& Pianta, 2011). Moreover, receiving instructional support - i.e. the richness of the instruction and feedback provided - is related to the students' skills in seeking out and maintaining peer relationships (Luckner \& Pianta, 2011; Welsh, Parke, Widaman, \& O'Neil, 2001).

\subsection{The stability of students' emotional engagement}


The emotional engagement of students in teacher-student and peer relationships has been found to be quite stable and predictable (Hughes, Luo, Kwok, \& Loyd, 2008; Hughes \& Chen, 2011; Li \& Lerner, 2013). Even if a student's classmates change, he/she tends to elicit relatively consistent reactions across the peer groups and attains a similar level of social status in a variety of groups (Bukowski \& Newcomb, 1984; Coie \& Kupersmidt, 1983; Hardy, Bukowski, \& Sippola, 2002; Terry \& Coie, 1991). The stability of teacher-student relationships has also been found to be somewhat high (Hughes et al., 2008; Jerome, Hamre, \& Pianta, 2009; O'Connor, 2010). However, a student's sense of belonging has been shown to decline across the course of the student's school years (Anderman, 2003; Anderman \& Anderman, 1999). The sense of belonging among primary school students tends to be universally higher compared to that of secondary school students (Fredricks et al., 2004). In particular, the primary-secondary school transition has been shown to be critical for the development of a student's sense of belonging (Eccles et al., 1993).

The stage-environment misfit resulting from the differences between the primary and secondary school environments has been proposed to be a reason for the decline in the sense of belonging among the upper-grade students (Eccles et al., 1993; Eccles \& Roeser, 2011; Wang \& Eccles, 2013). At the end of primary school, students typically have shared a long history with their teacher and their classmates. For several years, they have spent most of their time within the same peer group and with their own class teacher, primarily in their own class. At its best, the long-term relationships with their teacher and classmates have enabled students to engage in an intimate and secure social learning environment (Coffey, 2013) in which they are encouraged to take social and academic risks and participate actively in learning (Birch \& Ladd, 1998; Hamre \& Pianta, 2001; Luckner \& Pianta, 2011). At the beginning of secondary school, students need to adjust to a new and more diverse social environment, consisting of a larger peer network and a greater number of teachers (Coffey, 2013; Elias, 2001). In the more complex social environment, they do not necessary know their classmates and teachers as well as in primary school (Wells, 1996), and hence it can be more difficult to achieve the same level of emotional engagement (Anderman, 2003; L. W. Anderson, Jacobs, Schramm, \& Splittgerber, 2000; Scott, Rock, Pollack, \& Ingels, 1995). The multiple pedagogical interactions and activities provided by the secondary school environment challenge students to recognize expectations of multiple teachers and peers and to adjust 
their interests and behaviours accordingly (Elias, 2001). This requires the students to use more diverse and sophisticated social strategies (Ulmanen, Soini, Pyhältö, \& Pietarinen, 2014; Vaz et al., 2015). Especially for the students equipped with less refined academic and social skills, it can be more difficult to engage with peers and the network of teachers (L. W. Anderson et al., 2000; Berndt \& Mekos, 1995; Scott et al., 1995) in a way that results in a strong sense of belonging (Vaz et al., 2015). The diversity of the social environment also has benefits. The more capable and independent students are likely to benefit from the challenging social environment (Fredricks et al., 2004). In addition, problems in a studentteacher relationship can be compensated for with a functional relationship with other teachers. Hence, a positive teacher-student relationship can break the downward spiral of disengagement (D. H. Anderson, Nelson, Richardson, Webb, \& Young, 2011). Accordingly, the primary and secondary school environments involve contextual differences, thus providing both opportunities and challenges for the development of students' emotional engagement. Little is known about teachers' opportunities to influence peer relationships in different contexts.

\section{The aim of the study}

The development of students' emotional engagement is explored by analysing how the internal dynamics of students' sense of belonging in peer-group and teacher-student interaction evolve over three terms among two student groups: primary and secondary school students. The following hypotheses were tested:

1. Emotional engagement in terms of a sense of belonging to the peer group (EPG) at earlier grades predicts later EPG across different student cohorts (Hardy et al., 2002; Hughes \& Chen, 2011).

2. Emotional engagement in terms of a sense of belonging in teacher-student relationships (ETS) at earlier grades predicts later ETS across different student cohorts (Hughes et al., 2008; Hughes \& Chen, 2011; Li \& Lerner, 2013). 
3. Emotional engagement in terms of a sense of belonging in teacher-student relationships is associated with, and further, explains, perceived peer-group relations over time (Gest \& Rodkin, 2011; Hughes \& Chen, 2011; Luckner \& Pianta, 2011).

\section{[HERE FIGURE 1.]}

Figure 1. The hypothesized autoregressive model with the crossed effects of students' sense of belonging over time

\section{Methods}

\subsection{Participants and procedure}

The data were collected from the students of three compulsory comprehensive schools around Finland. One of the schools includes grades 1-6 (aged 7-12 years), and the other two schools include both primary and secondary levels, covering grades 1-9 (aged 7-15). At the schools covering grades 1-9, students also go through a transition, including an increase in the numbers of teachers and the diversity of peer relations. The schools are typical Finnish schools situated in suburban areas. The student population of the case schools ranged from 345 to 650 students. Two cohorts of students were included in the study: I) students at the end of primary school age and II) students at the beginning of secondary school. Cohort I consisted of 79 fifth-graders (aged 12-13). Cohort II consisted of 91 seventh-graders (aged 13-14). All fifth- and seventh-grade students from the case schools participated in the study, comprising a total of 170 students (girls: 55\% and boys: 45\%). Both student cohorts completed the emotional and cognitive engagement and school-related well-being (ECW) survey three times over the follow-up time of three consecutive academic terms (spring 2010, autumn 2010, and spring 2011) (Pietarinen, Soini, \& Pyhältö, 2014).

The data were collected by the researchers during their fieldwork in the case study schools. The 
researchers gave the students instructions, both in writing and verbally, on how to complete the survey. The students completed the survey in 15-20 minutes. Before conducting the survey, teachers, parents, and students were informed about the project. Research permits were collected from the schools and the parents gave their informed consent for their children to participate in the study. The written responses were collected by the researchers, and the responses were then coded into SPSS files by two trained research assistants.

\subsection{Instrument}

The data were collected using a survey that measures comprehensive school students' experienced emotional and cognitive engagement and school-related well-being (ECW) (Pietarinen et al., 2014). The ECW questionnaire was constructed, tested, and further developed by Pietarinen and colleges on the basis of the results of an open-ended survey of ninth graders and two pilot studies with 228 comprehensive school students in addition to feedback received from students, teachers, researchers, and academics. Ambiguous items were revised according to the comments received. Moreover, the components of emotional engagement, experienced well-being, and the one-dimensional structures of cognitive engagement were identified with exploratory factor analysis (EFA) and principal axis factoring (PAF) (Pietarinen et al., 2014). As a result of the factor analysis, the original scale of emotional engagement shortened and all reversed items of emotional engagement, such as "I wish I was in a different class", were excluded (see also Pietarinen et al., 2014).

The ECW survey data derives from 13 statements about emotional engagement. Socio-demographic background information was elicited about the students' age, gender, and school grade. Students' emotional engagement was measured with the two complementary scales of 1) peer-group relations and 2) teacher-student relations, which describe the students' sense of belonging, especially in terms of the positive effects of social relations in two social contexts. The peer interaction scale assessed social cohesion among students and the students' sense of being accepted and respected among other students (Goodenow, 1993). It consisted of five items, such as "I feel the other students like me" and "We have a nice class spirit”. The teacher-student interaction scale assessed individual students' perceptions of 
teachers' emotionally supportive behaviour towards students, such as the teachers' way of encouraging students and showing empathy, trust, and appreciation (Lee, 2012; Pakarinen et al., 2010; Roeser et al., 1996). In addition, it assessed the teachers' instructional support towards students, such as the aptness of the instruction (Luckner \& Pianta, 2011; Welsh et al., 2001). The teacher-student interaction scale consisted of eight items, such as "I feel the teachers care about me", "The teacher often gives me encouraging feedback", "In our school the teachers listen to the pupils”, and "Most teachers know how to teach”. Both of the scales were measured on a Likert scale ranging from 1 (strongly disagree) to 5 (strongly agree). In Table 1, Cronbach's alphas are presented for both scales at the different time points (i.e. each term).

\subsection{Data analyses}

The hypothesized model tested is illustrated in Figure 1. The path models were constructed with the Mplus 6.12 program (Muthén \& Muthén, 1998-2015) using structural equation modelling (SEM). Path analysis results were calculated with the MLR estimator to account for the non-normality of the study variables. Several fit indices were used to test model fit, including the $\chi^{2}$ test, comparative fit index (CFI), TuckerLewin Index (TLI), root mean square error of approximation (RMSEA), and standardized root mean square error of approximation (SRMR). A nonsignificant $\chi^{2}$ value, CFI and TLI values above .95, a RMSEA value below .06, and a SRMR value below .08 indicate a good fit with the data (Muthén \& Muthén, 1998-2010). The specificity of the longitudinal path model in terms of the students' emotional engagement was further analysed by testing model fit in the different student cohorts (Little, Card, Bovaird, Preacher, \& Crandall, 2007). The analysis was conducted in two phases. Firstly, the hypotheses were tested within the whole sample (Model 1). After this, phase 2 tested whether the stability of variables and the association between variables also existed in school grade cohorts (Model 2 and 3). The models are depicted in Figures 2 and 3. The level and average change of the experienced emotional engagement in the peer and teacher-student relations were analysed with a $t$ - Test across the three academic terms. 


\section{Results}

Table 1 shows the correlations of the subscales and Cronbach's alphas for each scale. The results show the expected correlations within the peer relationships (EPG1-EPG3) and the teacher-student relationships (ETS1-ETS3) as well as between these two subscales. The correlations were statistically significant in the expected directions, excluding the correlation between EPG1 and ETS3. Statistically significant correlations ranged from .17 to .60 for the whole data.

Table 1. Descriptive statistics ( $\mathrm{n}=170)$ (whole data).

\section{[HERE TABLE 1.]}

\subsection{The stability of emotional engagement in the students' school path}

The aim of the study was to examine the evolution of the internal dynamics of the students' emotional engagement in peer-group and teacher-student relations during the three terms. Our presumption was that emotional engagement in terms of a sense of belonging remains stable over time (Hypotheses 1 and 2). We also hypothesized that emotional engagement in teacher-student relations is associated with emotional engagement in peer-group relations at every time point in the students' school path (hypothesis 3). As Figure 2 shows, the tested Model 1 fitted the whole data (see Figure 2; $\chi^{2}(6, n=178)=9.64, p=.14$, RMSEA=.06, CFI=.99, TLI=.97, SRMR=.05). Accordingly, the results confirmed that the students' emotional engagement in peer-group and in teacher-student relations was relatively stable. However, the stability of the emotional engagement with peers and in student-teacher interaction varied over time. Emotional engagement - i.e. the sense of belonging over time - in the student-teacher relationships was more predictable than in peer relationships. Accordingly, the results confirmed Hypotheses 1 and 2.

Further investigation showed that the sense of belonging in the teacher-student relationships (ETS) was associated with the sense of belonging in peer relationships and furthermore explained the perceived 
peer-group relations (EPG) over time (see Figure 2). The results indicated that the sense of belonging constructed in the teacher-student relationships promoted positive peer influences during the school path. The results confirmed Hypothesis 3.

\section{[HERE FIGURE 2.]}

Figure 2. Standardized path diagram of the autoregressive model with time-lagged effects showing the association between the students' sense of belonging in teacher-student interaction (ETS) and in peer interaction (EPG) among compulsory school students (whole data).

\subsection{Specificity of emotional engagement in terms of the school grade differences}

After analysing the hypotheses using the whole data, the differences in the development of students' emotional engagement between primary and secondary school students were explored (Model 2). The specified model is shown in Figure 3: the model had a good fit $\left(\chi^{2}(12, n=178)=12.63, p=.40\right.$, RMSEA $=.02, \mathrm{CFI}=1.00, \mathrm{TLI}=.99, \mathrm{SRMR}=.05$ ). The results confirmed hypotheses 1 and 2 , showing that students' emotional engagement in peer-group and teacher-student relationships was relatively stable over time within both student cohorts (Figure 3). However, there were some differences between primary and secondary school students. Firstly, students' emotional engagement in the peer group was more predictable among secondary school students than among primary school students. Among the primary school students, emotional engagement in the peer group (EPG) did not predict EPG a year later, whereas among the secondary school students, such predictability occurred. Secondly, differences in the predictability of students' emotional engagement in the teacher-student relationships were also detected. Among the primary school students, the predictability of the students' emotional engagement in the teacher-student relationship weakened over time, while among the secondary school students, it strengthened over time. Moreover, among the secondary school students, the relationship in 
teacher-student relations between terms 1 and 3 was the opposite of that among the primary school students. This is explained by the high variation in the sense of belonging in teacher-student relationships within primary school students (see Table 2).

The results also show that the teacher-student relationships better explained perceived peer-group relationships among secondary school students than among primary schools students. The experienced teacher-student relationships did not explain peer-group relations statistically significantly at time point 3 (the third term) among the primary school students (see Figure 3). Instead, for secondary school students, the teacher-student relationships explained the perceived peer-group relations (EPG) over time.

[HERE FIGURE 3.]

Figure 3. Specified model in terms of the student cohorts from primary school level (from fifth to sixth grade) and secondary school level (from seventh to eighth grade) (Primary/Secondary).

\subsection{The difference and changes in the levels of experienced emotional engagement across time}

School grade comparisons show that primary school students were statistically significantly more emotional engaged in teacher-student relationships than secondary school students at every time point (see Table 2). No statistically significant grade-related differences were found regarding the level of the sense of belonging in peer-group relations.

Table 2. School grade differences

[HERE TABLE 2.] 
Table 3 shows the statistically significant changes within school-grade groups. Some differences between primary and secondary school students existed. At the end of primary school, the students' sense of belonging in teacher-student relations weakened statistically significantly at every time point, whereas in secondary school, it strengthened statistically significantly at the beginning of eighth grade (T1-T2), but weakened statistically significantly at the end of the eighth grade (T2-T3). Secondary school students' emotional engagement in peer-group relations weakened statistically significantly during over the year (T1-T3). In primary school, such a change was not detected.

Table 3. Changes in experienced emotional engagement in terms of different school grades

[HERE TABLE 3.] 


\section{Discussion}

\subsection{Anatomy of emotional engagement}

The aim of the study was to examine the development of the internal dynamics of the students' emotional engagement in peer-group and teacher-student relations during the three school terms among primary and secondary school students. The models, which were tested with both whole data and with student cohorts, explored the stability of students' emotional engagement in teacher-student and peer-group relations and the association between the ingredients of emotional engagement during the three terms. The results show that students' emotional engagement is a stable construct (hypotheses 1 and 2), and that the students' emotional engagement in teacher-student relationships associates with emotional engagement in peer relations. Moreover, our study shows that students' prior experiences in teacher-student and peer-group relations predict their future experiences, although the students' emotional engagement in teacher-student relations was more stable than peer-group relations. The findings also confirmed the hypothesis that perceived emotional engagement in teacher-student relations goes hand in hand with students' emotional engagement in peer-group relations (Hypothesis 3). The findings contribute to previous research, suggesting that the experience of fair treatment and emotional support from teachers is a central determinant also for students’ peer relations (Gazelle, 2006; Hughes \& Chen, 2011; Luckner \& Pianta, 2011), although some differences between sub-groups existed.

Moreover, the results show that students' relationships with a peer group become more predictable during the students' sixth grade, whereas at the same time the predictability of teacher-student relationships weakens. This implies that students re-negotiate their relationships with the teacher towards the end of primary school, while their status in peer-group relations begins to stabilize. Combined with the fact that the sense of belonging in teacher-student relationships reduced towards the end of primary school, this may imply that students grow more independent and rely more on their peers than the teachers before the transfer to secondary school (Buhrmester \& Furman, 1987). As the senior students of the primary school (Coffey, 2013), they also have more responsibilities for their schoolwork, and they are expected to become more autonomous (Reeve \& Jang, 2006). 
The results imply that due to the changes occurring both in their social environment and in their academic aspirations and goals at the primary-secondary school transition, students are challenged to find a balance between the perceived support needed from teachers and the expected autonomy in various school tasks (Cillessen \& Mayeux, 2007; Pietarinen, Pyhältö, \& Soini, 2010; Zimmer-Gembeck, Chipuer, Hanisch, Creed, \& McGregor, 2006). However, our previous study showed that at the end of the sixth grade, students did not report the use of active social strategies to modify teacher-student interaction (Ulmanen et al., 2014). This, in turn, may result in a misfit between the students' emotional needs and the school's social environment, and further, contribute to disengagement from schoolwork (Eccles et al., 1993).

It is noteworthy that in spite of the greater diversity of teachers in secondary schools, the teacher-student relationships became more stable during students' eighth grade. Moreover, it can be considered encouraging that at the beginning of the students' eighth grade, teachers-students relations were strengthened, even though the sense of belonging in teacher-student relationships weakened towards the end of the eighth grade. A reason for this may be that at the beginning of secondary school, students are more responsive and dependent on supportive teacher-student relationships in the new environment than later when they have adapted to the new environment. At the beginning of secondary school, students likely need more support from their teachers due to the greater choice in coursework and greater responsibility for schoolwork, and they are hence more open and receptive to the teachers' guidance and instructions; thus, students may experience higher levels of a sense of belonging in teacher-student relationships (Eccles \& Roeser, 1999).

The decrease in the sense of belonging in teacher-student relationships towards the end of eighth grade may suggest that students have successfully adjusted to the new environment in terms of the quality of teacher-student interaction (Eccles et al., 1993). Respectively, students' sense of belonging in peer relations seems to undergo greater reorganization during the eighth grade. This is likely to be at least partly caused by the choices students make to study different additional courses. It may also reflect the general social turbulence caused by the school transition, challenging the old social structure and 
relationships, and providing opportunities to create new ones. Hence, school transition appears to be a significant point in terms of emotional engagement.

All in all, the results suggest that the perceived quality of teacher-student interaction is related to the quality of peer relationships. Furthermore, the results showed - contrary to earlier findings (Bierman, 2011) - that the association between teacher-student and peer-group relations was stronger among the secondary school students than among the primary school students. In prior studies, the experienced sense of belonging in teacher-student interaction was found to associate directly with students' affects towards schoolwork and the valuing of schoolwork (A. R. Anderson et al., 2004; Furrer \& Skinner, 2003; Klem \& Connell, 2004; Lee, 2012; Patrick et al., 2007; Roeser et al., 1996). Our findings show that the sense of belonging in the teacher-student relationships also plays a central role in students' sense of belonging in peer relationships, and hence in student emotional engagement. This implies that despite the social turbulence before and after the transition to secondary school, teachers have real opportunities to influence not only the quality of teacher-student interaction, but also and especially the students' peer relationships in everyday school practices.

\subsection{Implications for the school's pedagogical practices: the students' perspective}

The findings imply that the teachers' sensitivity, interest in the students' development, ability to understand the students' perspectives, and respectful and fair treatment of students were acknowledged by students as core factors contributing to a sense of belonging in teacher-student and, even more strongly, in peer relations in the school community. However, the significance of the teacher and peer relations for the students' emotional engagement, especially in terms of a sense of belonging, seems to vary at different phases of the school path. This, in turn, challenges the pedagogical practices of schools in supporting the favourable development of the students' emotional engagement.

More specifically, the results imply that the core factors contributing in the students' sense of belonging in the school community are in fact significantly embedded in the instructional practices adopted in the classroom. Teachers seem to provide a significant model of accepted social behaviours and create an 
environment not only for practising the ways of learning concerning different domains at the classroom level, but in particular for learning the social skills needed for constructing and maintaining the balance between the student's emotional needs and the school's social environment at the individual level.

Hence, the students' emotional engagement is not a predetermined or consistent state of mind in terms of perceived competencies, expectations, and attitudes related to participating and studying at school. It is a precondition for meaningful learning that is constructed in teacher-student relations embedded in the instructional decisions and behaviour adopted by teacher, such as giving encouraging feedback or taking account of the students' initiatives during the lessons. This, in turn, also seems to influence the quality of peer relationships outside of the classroom, for instance the estimated stability of significant peer relations. The relational nature of these two social contexts in terms of facilitating the students' sense of belonging in the school community regulate the extent to which they feel being personally accepted, respected, and supported both by the teachers and by peers.

The school path includes expected and normative transitions experienced by students, such as the transfer to secondary school, that seem to challenge the balance of the social context, and hence students' perceived emotional engagement. The dynamic and evolving nature of the students' emotional engagement challenges teachers to reflect on their instructional decisions and behaviour in terms of supporting emotional engagement. However, understanding the interrelations and developmental processes of a sense of belonging also helps school communities to anticipate and plan pedagogical practices in order to promote collaborative learning processes that increase positive interdependency between students, and, furthermore, encourage them to monitor the quality of the teacher-student relationship individually in terms of each student in the classroom.

\subsection{Limitations of the study}

This longitudinal study aimed to explore the stability of students' emotional engagement in teacher-student and peer-group relations. The association between the ingredients of emotional engagement over time was also analysed (from grades five to six and from grades seven to eight). The 
validity and reliability of the ECW survey was satisfactory (Pietarinen et al., 2014). In addition, the validity and reliability of the analysed scales of emotional engagement in teacher-student and peer interaction were satisfactory. However, further construct validation of the scales is needed: the scales have not been validated in other countries, school systems, or environments (Pietarinen et al., 2014). Furthermore, the complexity of the interrelations between the different ingredients of emotional engagement needs to be studied further.

Path analysis confirmed a pattern of correlations that explained the students' experienced emotional engagement. However, causality between the ingredients of emotional engagement cannot be interpreted on the basis of these findings (Lleras, 2005). To test teacher influence on peer relations, its mediating effects need to be considered in future studies. Despite the limitations, our study provides important information on the development of students' emotional engagement in terms of a sense of belonging in teacher-student and peer relations in two different contexts, namely the primary and secondary school.

\section{References}

Anderman, L. H. (2003). Academic and social perceptions as predictors of change in middle school students' sense of school belonging. Journal of Experimental Education, 72(1), 5-22.

Anderman, L. H., \& Anderman, E. M. (1999). Social predictors of changes in students' achievement goal orientations. Contemporary Educational Psychology, 24(1), 21-37. doi:http://dx.doi.org/10.1006/ceps.1998.0978

Anderson, D. H., Nelson, J. A. P., Richardson, M., Webb, N., \& Young, E. L. (2011). Using dialogue journals to strengthen the student-teacher relationship: A comparative case study Project Innovation, Inc. 
Anderson, A. R., Christenson, S. L., Sinclair, M. F., \& Lehr, C. A. (2004). Check \& connect: The importance of relationships for promoting engagement with school. Journal of School Psychology, 42(2), 95-113. doi:http://dx.doi.org/10.1016/j.jsp.2004.01.002

Anderson, L. W., Jacobs, J., Schramm, S., \& Splittgerber, F. (2000). School transitions: Beginning of the end or a new beginning? International Journal of Educational Research, 33(4), 325-339. doi:http://dx.doi.org/10.1016/S0883-0355(00)00020-3

Appleton, J. J., Christenson, S. L., \& Furlong, M. J. (2008). Student engagement with school: Critical conceptual and methodological issues of the construct. Psychology in the Schools, 45(5), 369-386. doi:10.1002/pits.20303

Bagwell, C. L., Newcomb, A. F., \& Bukowski, W. M. (1998). Preadolescent friendship and peer rejection as predictors of adult adjustment. Child Development, 69(1), 140.

Battistich, V., \& Solomon, D. (1997). Caring school communities. Educational Psychologist, 32(3), 137.

Battistich, V., Solomon, D., Watson, M., \& Schaps, E. (1997). Caring school communities. Educational Psychologist, 32(3), 137-151. doi:10.1207/s15326985ep3203_1

Berndt, T. J., Hawkins, J. A., \& Jiao, Z. (1999). Influences of friends and friendships on adjustment to junior high school. Merrill-Palmer Quarterly, 45(1), 13-41.

Berndt, T. J., \& Mekos, D. (1995). Adolescents' perceptions of the stressful and desirable aspects of the transition to junior high school. Journal of Research on Adolescence (Lawrence Erlbaum), 5(1), 123-142.

Bierman, K. L. (2011). The promise and potential of studying the "invisible hand" of teacher influence on peer relations and student outcomes: A commentary. Journal of Applied Developmental Psychology, 32(5), 297-303. doi:http://dx.doi.org/10.1016/j.appdev.2011.04.004 
Birch, S. H., \& Ladd, G. W. (1998). Children's interpersonal behaviors and the teacher-child relationship. Developmental Psychology, 34(5), 934-946. doi:http://helios.uta.fi:2165/10.1037/0012-1649.34.5.934

Brown, B. B., Eicher, S. A., \& Petrie, S. (1986). The importance of peer group (“crowd”) affiliation in adolescence. Journal of Adolescence, 9(1), 73-96. doi:http://dx.doi.org/10.1016/S0140$\underline{1971(86) 80029-X}$

Buhrmester, D., \& Furman, W. (1987). The development of companionship and Intimacy $<b r />$. Child Development, 58(4), 1101-1113.

Bukowski, W. M., \& Newcomb, A. F. (1984). Stability and determinants of sociometric status and friendship choice: A longitudinal perspective<br /> Developmental Psychology, 20(5), 941-952. doi:doi:http://dx.doi.org.helios.uta.fi/10.1037/0012-1649.20.5.941

Cameron, C. E., Connor, C. M., \& Morrison, F. J. (2005). Effects of variation in teacher organization on classroom functioning. Journal of School Psychology, 43(1), 61-85.

doi:http:/helios.uta.fi:2122/10.1016/j.jsp.2004.12.002

Cillessen, A. H. N., \& Mayeux, L. (2007). Expectations and perceptions at school transitions: The role of peer status and aggression. Journal of School Psychology, 45(5), 567-586. doi:http://dx.doi.org/10.1016/j.jsp.2007.05.004

Coffey, A. (2013). Relationships: The key to successful transition from primary to secondary school? Improving Schools, 16(3), 261-271. doi:10.1177/1365480213505181

Coie, J. D., \& Kupersmidt, J. B. (1983). A behavioral analysis of emerging social status in boys' groups. Child Development, 54(6), 1400-1416. doi:doi:10.1111/1467-8624.ep12418487

Crespo, C., Jose, P. E., Kielpikowski, M., \& Pryor, J. (2013). "On solid ground": Family and school connectedness promotes adolescents' future orientation. Journal of Adolescence, 36, 993-1002. 
Debnam, K. J., Johnson, S. L., Waasdorp, T. E., \& Bradshaw, C. P. (2014). Equity, connection, and engagement in the school context to promote positive youth development. Journal of Research on Adolescence, 24(3), 447-459. doi:10.1111/jora.12083

Downer, J. T., Booren, L. M., Lima, O. K., Luckner, A. E., \& Pianta, R. C. (2010). The individualized classroom assessment scoring system (inCLASS): Preliminary reliability and validity of a system for observing preschoolers’ competence in classroom interactions. Early Childhood Research Quarterly, 25(1), 1-16. doi:http://dx.doi.org/10.1016/j.ecresq.2009.08.004

Dupont, S., Galand, B., Nils, F., \& Hospel, V. (2014). Social context, self-perceptions and student engagement: A SEM investigation of the self-system model of motivational development (SSMMD). Electronic Journal of Research in Educational Psychology, 12(1), 5-32.

Eccles, J. S., Midgley, C., Wigfield, A., Buchanan, C. M., Reuman, D., Flanagan, C., \& Mac Iver, D. (1993). Development during adolescence: The impact of stage-environment fit on young adolescents' experiences in schools and in families. American Psychologist, 48(2), 90-101. doi:10.1037/0003-066X.48.2.90

Eccles, J. S., \& Roeser, R. W. (1999). School and community influences on human development. In M. H. Bornstein M. E. Lamb (Ed.), (pp. 503-554). Mahwah, NJ, US: Lawrence Erlbaum Associates Publishers.

Eccles, J. S., \& Roeser, R. W. (2011). Schools as developmental contexts during adolescence. Journal of Research on Adolescence, 21(1), 225-241. doi:10.1111/j.1532-7795.2010.00725.x

Elffers, L., Oort, F. J., \& Karsten, S. (2012). Making the connection: The role of social and academic school experiences in students' emotional engagement with school in post-secondary vocational education. Learning and Individual Differences, 22(2), 242-250. doi:http://dx.doi.org/10.1016/j.lindif.2011.08.005

Elias, M. J. (2001). Easing transitions with social-emotional learning. Principal Leadership, 1(7), 20-25. 
Finn, J. D. (1989). Withdrawing from school. Review of Educational Research, 59(2), 117-142.

Fredricks, J. A., Blumenfeld, P. C., \& Paris, A. H. (2004). School engagement: Potential of the concept, state of the evidence. Review of Educational Research, 74(1), 59-109.

Furrer, C., \& Skinner, E. A. (2003). Sense of relatedness as a factor in children's academic engagement and performance. Journal of Educational Psychology, 95(1), 148.

Gazelle, H. (2006). Class climate moderates peer relations and emotional adjustment in children with an early history of anxious solitude: A child × environment model. Developmental Psychology, 42(6), 1179-1192. doi:10.1037/0012-1649.42.6.1179

Gest, S. D., Graham-Bermann, S. A., \& Hartup, W. W. (2001). Peer experience: Common and unique features of number of friendships, social network centrality, and sociometric status. Social Development, 10(1), 23-40. doi:10.1111/1467-9507.00146

Gest, S. D., \& Rodkin, P. C. (2011). Teaching practices and elementary classroom peer ecologies. Journal of Applied Developmental Psychology, 32(5), 288-296. doi:http://dx.doi.org/10.1016/j.appdev.2011.02.004

Gonida, E. N., Voulala, K., \& Kiosseoglou, G. (2009). Students' achievement goal orientations and their behavioral and emotional engagement: Co-examining the role of perceived school goal structures and parent goals during adolescence. Learning and Individual Differences, 19(1), 53-60. doi:http://dx.doi.org/10.1016/j.lindif.2008.04.002

Goodenow, C. (1993). The psychological sense of school membership among adolescents: Scale development and educational correlates. Psychology in the Schools, 30(1), 79-90. doi:10.1002/1520-6807(199301)30:1<79::AID-PITS2310300113>3.0.CO;2-X

Hallinan, M. T., \& Williams, R. A. (1990). Students' characteristics and the peer-influence process. Sociology of Education, 63(2), 122-132. 
Hamre, B. K., \& Pianta, R. C. (2001). Early Teacher-Child relationships and the trajectory of children's school outcomes through eighth grade. Child Development, 72(2), 625.

Hardy, C. L., Bukowski, W. M., \& Sippola, L. K. (2002). Stability and change in peer relationships during the transition to middle-level school. The Journal of Early Adolescence, 22(2), 117-142. doi:10.1177/0272431602022002001

Harel-Fisch, Y., Walsh, S. D., Fogel-Grinvald, H., Amitai, G., Pickett, W., Molcho, M., . . Craig, W. (2011). Negative school perceptions and involvement in school bullying: A universal relationship across 40 countries. Journal of Adolescence, 34, 639-652.

Hoffman, M., Richmond, J., Morrow, J., \& Kandice, S. (2002). Investigating “sense of belonging” in first-year college students. Journal of College Student Retention, 4, 227-256.

Howes, C., \& Hamilton, C. E. (1994). Children's relationships with peers: Differential associations with aspects of the teacher-child relationship. Child Development, 65(1), 253-263. doi:10.1111/14678624.ep9406130693

Hughes, J. N., Luo, W., Kwok, O. -., \& Loyd, L. K. (2008). Teacher-Student support, effortful engagement, and achievement: A 3-year longitudinal study. Journal of Educational Psychology, 100(1), 1-14. doi:http://doi.org/10.1037/0022-0663.100.1.1

Hughes, J. N., \& Chen, Q. (2011). Reciprocal effects of student-teacher and student-peer relatedness: Effects on academic self efficacy. Journal of Applied Developmental Psychology, 32(5), 278-287. doi:http://dx.doi.org/10.1016/j.appdev.2010.03.005

Israelashvili, M. (1997). School adjustment, school membership and adolescents' future expectations. Journal of Adolescence, 20(5), 525-535. doi:http://dx.doi.org/10.1006/jado.1997.0107 
Jerome, E. M., Hamre, B. K., \& Pianta, R. C. (2009). Teacher-child relationships from kindergarten to sixth grade: Early childhood predictors of teacher-perceived conflict and closeness $<\mathbf{b r} />$. Social Development, 18(4), 915-945. doi:10.1111/j.1467-9507.2008.00508.x

Kiuru, N., Aunola, K., Nurmi, J., Leskinen, E., \& Salmela-Aro, K. (2008). Peer group influence and selection in adolescents' school burnout. Merrill-Palmer Quarterly, 54(1), 23-55.

Klem, A. M., \& Connell, J. P. (2004). Relationships matter: Linking teacher support to student engagement and achievement. Journal of School Health, 74(7), 262-273. doi:10.1111/j.17461561.2004.tb08283.x

Ladd, G., W. (1999). Peer relationships and social competence during early and middle childhood. Annual Review of Psychology, 50, 333-359. doi:10.1146/annurev.psych.50.1.333

Lee, J. (2012). The effects of the teacher-student relationship and academic press on student engagement and academic performance. International Journal of Educational Research, 53(0), 330-340. doi:http://dx.doi.org/10.1016/j.ijer.2012.04.006

Li, Y., Lerner, J. V., \& Lerner, R. M. (2010). Personal and ecological assets and academic competence in early adolescence: The mediating role of school engagement. Journal of Youth and Adolescence, 39(7), 801-815.

Li, Y., \& Lerner, R. M. (2013). Interrelations of behavioral, emotional, and cognitive school engagement in high school students. Journal of Youth and Adolescence, 42(1), 20-32.

Little, T. D., Card, N. A., Bovaird, J. A., Preacher, K. J., \& Crandall, C. S. (2007). Structural equation modeling of mediation and moderation with contextual factors. In T. D. Little, J. A. Bovaird \& N. A. Card (Eds.), Modeling contextual effects in longitudinal studies (pp. 207-230). Mahwah, New Jersey: Routledge. 
Lleras, C. (2005). Path analysis. In K. Kempf-Leonard (Ed.), Encyclopedia of social measurement (pp. 25-30). New York: Elsevier. doi:http://dx.doi.org/10.1016/B0-12-369398-5/00483-7

Luckner, A. E., \& Pianta, R. C. (2011). Teacher-student interactions in fifth grade classrooms: Relations with children's peer behavior. Journal of Applied Developmental Psychology, 32(5), 257266. doi:http://dx.doi.org/10.1016/j.appdev.2011.02.010

Muthén, L. K., \& Muthén, B. O. (1998-2015). Mplus user's guide. statistical analysis with latent variables (7th ed.). Los Angeles: CA: Muthén \& Muthén.

O'Connor, E. (2010). Teacher-child relationships as dynamic systems. Journal of School Psychology, 48(3), 187-218. doi:http://dx.doi.org/10.1016/j.jsp.2010.01.001

Pakarinen, E., Lerkkanen, M., Poikkeus, A., Kiuru, N., Siekkinen, M., Rasku-Puttonen, H., \& Nurmi, J. (2010). A validation of the classroom assessment scoring system in finnish kindergartens. Early Education and Development, 21(1), 95-124. doi:10.1080/10409280902858764

Patrick, H., Ryan, A. M., \& Kaplan, A. (2007). Early adolescents' perceptions of the classroom social environment, motivational beliefs, and engagement. Journal of Educational Psychology, 99(1), 8398. doi:10.1037/0022-0663.99.1.83

Pietarinen, J., Pyhältö, K., \& Soini, T. (2010). A horizontal approach to school transitions: A lesson learned from finnish 15-year-olds. Cambridge Journal of Education, 40(3), 229-245. doi:10.1080/0305764X.2010.506145

Pietarinen, J., Soini, T., \& Pyhältö, K. (2014). Students' emotional and cognitive engagement as the determinants of well-being and achievement in school. International Journal of Educational Research, 67(0), 40-51. doi:http://dx.doi.org/10.1016/j.jjer.2014.05.001

Reeve, J., \& Jang, H. (2006). What teachers say and do to support students' autonomy during a learning activity. Journal of Educational Psychology, 98(1), 209-218. doi:10.1037/0022-0663.98.1.209 
Roeser, R. W., Midgley, C., \& Urdan, T. C. (1996). Perceptions of the school psychological environment and early adolescents' psychological and behavioral functioning in school: The mediating role of goals and belonging. Journal of Educational Psychology, 88(3), 408-422. doi:10.1037/0022-0663.88.3.408

Sagayadevan, V., \& Jeyaraj, S. (2012). The role of emotional engagement in lecturer-student interaction and the impact on academic outcomes of student achievement and learning. Jounral of the Scholarship of Teaching and Learning, 12(3), 1-30.

Sage, N. A., \& Kindermann, T. A. (1999). Peer networks, behavior contingencies, and children’s engagement in the classroom. Merrill-Palmer Quarterly, 45(1), 143-171.

Scott, L. A., Rock, D. A., Pollack, J. M., \& Ingels, S. J. (1995). Two years later: Cognitive gains and school transitions of NELS: 88 eighth graders. national education longitudinal study of 1988. (Statistical Analysis Report). Washington, DC: National Center for Educational Statistics.

Spilt, J. L., Hughes, J. N., Wu, J. -., \& Kwok, O. -. (2012). Dynamics of teacher-student relationships: Stability and change across elementary school and the influence on children's academic success. Child Development, 83(4), 1180-1195. doi:http://doi.org/10.1111/j.1467-8624.2012.01761.x

Terry, R., \& Coie, J. D. (1991). A comparison of methods for defining sociometric status among children . Developmental Psychology, 27(5), 867-880. doi:doi:http://dx.doi.org.helios.uta.fi/10.1037/0012-1649.27.5.867

Ulmanen, S., Soini, T., Pyhältö, K., \& Pietarinen, J. (2014). Strategies for academic engagement perceived by finnish sixth and eighth graders. Cambridge Journal of Education, 44(3), 425-443. doi:10.1080/0305764X.2014.921281

Vaz, S., Falkmer, M., Ciccarelli, M., Passmore, A., Parsons, R., Black, M., . . . Falkmer, T. (2015). Belongingness in early secondary school: Key factors that primary and secondary schools need to consider. PLoS ONE, 10(9), 1-27. doi:10.1371/journal.pone.0136053 
Wang, M., \& Eccles, J. S. (2013). School context, achievement motivation, and academic engagement: A longitudinal study of school engagement using a multidimensional perspective. Learning and Instruction, 28(0), 12-23. doi:http://dx.doi.org/10.1016/j.learninstruc.2013.04.002

Wang, M., Willett, J. B., \& Eccles, J. S. (2011). The assessment of school engagement: Examining dimensionality and measurement invariance by gender and race/ethnicity. Journal of School Psychology, 49(4), 465-480. doi:http://dx.doi.org/10.1016/j.jsp.2011.04.001

Wellborn, J. G., \& Connell, J. P. (Eds.). (1987). Student engagement and disaffection in school student report. . Rochester, NY: Rochester Assessment Package for Schools.

Wells, M. C. (1996). Literacies lost: When students move from a progressive middle school to a traditional high school. New York: Teacher College Press.

Welsh, M., Parke, R. D., Widaman, K., \& O'Neil, R. (2001). Linkages between children's social and academic competence: A longitudinal analysis. Journal of School Psychology, 39(6), 463-482. doi:http://helios.uta.fi:2096/10.1016/S0022-4405(01)00084-X

Wentzel, K. R. (1998). Social relationships and motivation in middle school: The role of parents, teachers, and peers. Journal of Educational Psychology, 90(2), 202-209. doi:10.1037/00220663.90.2.202

Wentzel, K. R., \& Asher, S. R. (1995). The academic lives of neglected, rejected, popular, and controversial children. Child Development, 66(3), 754-763. doi:10.1111/j.14678624.1995.tb00903.x

Zimmer-Gembeck, M., Chipuer, H. M., Hanisch, M., Creed, P. A., \& McGregor, L. (2006). Relationships at school and stage-environment fit as resources for adolescent engagement and achievement. Journal of Adolescence, 29(6), 911-933. doi:10.1016/j.adolescence.2006.04.008 
Zimmer-Gembeck, M., \& Locke, E. M. (2007). The socialization of adolescent coping behaviours:

Relationships with families and teachers. Journal of Adolescence, 30(1), 1-16.

doi:http://helios.uta.fi:2096/10.1016/j.adolescence.2005.03.001 


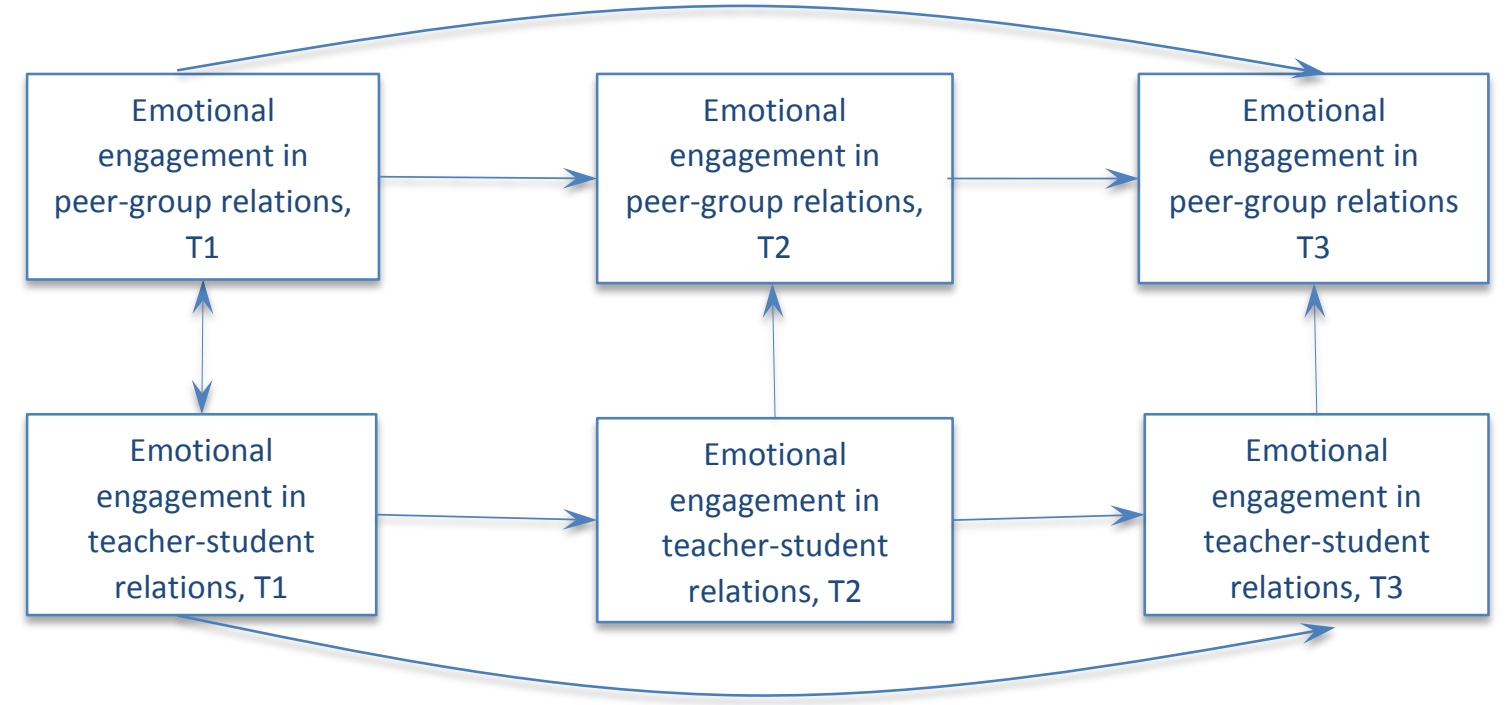

Figure 1. The hypothesized autoregressive model with the crossed effects of students' sense of belonging over time

ns.

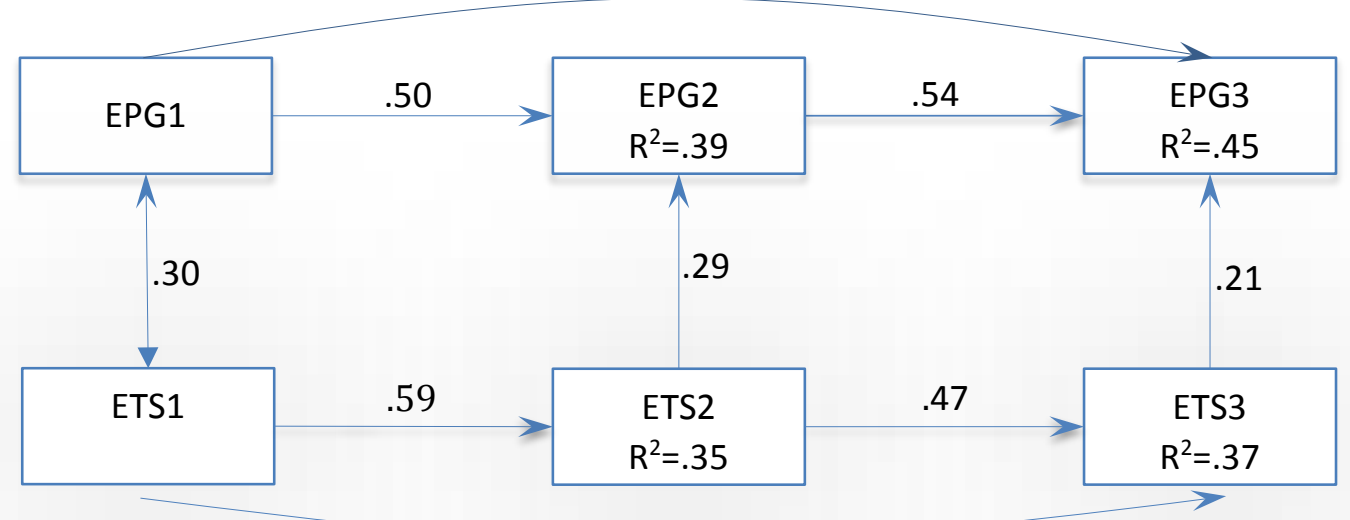

.19

Figure 2. Standardized path diagram of the autoregressive model with time-lagged effects showing the association between the students' sense of belonging in teacher-student interaction (ETS) and in peer interaction (EPG) among compulsory school students (whole data) 
ns./.22

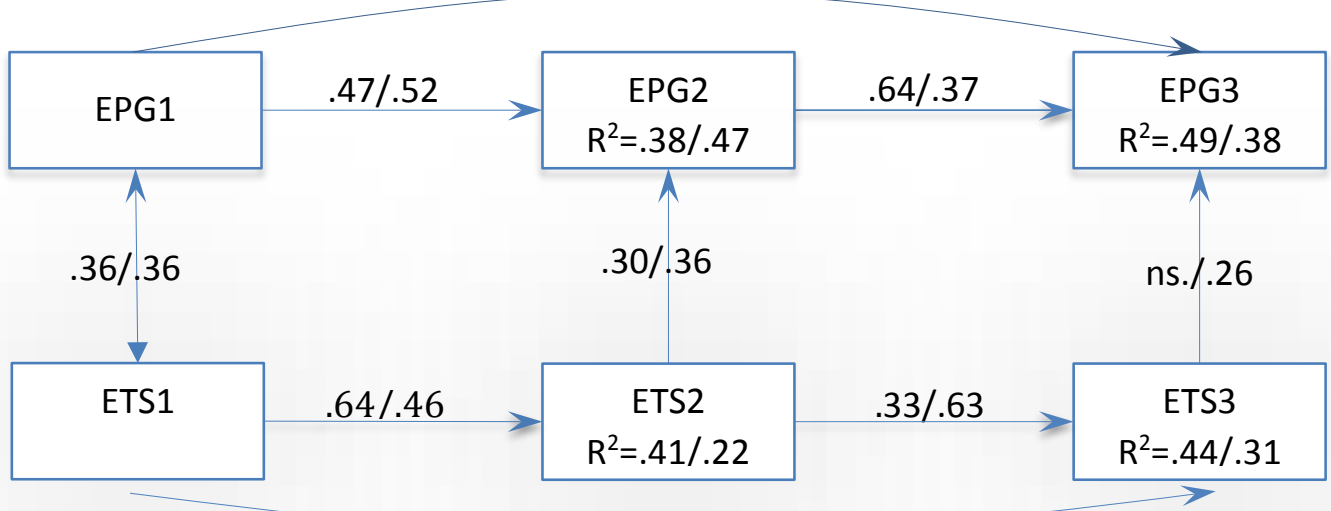

$.40 /-.28$

Figure 3. Specified model in terms of the student cohorts from primary school level (from fifth to sixth grade) and secondary school level (from seventh to eighth grade) (Primary/Secondary). EPG = peer-group relationships; ETS = teacher-student relationships 
Table 1. Descriptive statistics $(\mathrm{n}=170)$ (whole data)

\begin{tabular}{lcccccccc}
\hline & \multicolumn{9}{c}{ Correlations $(157-170)$} & Range & $\alpha$ \\
\cline { 2 - 6 } Sub-scales & 1 & 2 & 3 & 4 & 5 & 6 & & \\
\hline 1. EPG1 & - & & & & & & $1.00-5.00$ & .73 \\
2. EPG2 & $.54^{*}$ & - & & & & $1.00-5.00$ & .72 \\
3. EPG3 & $.37^{*}$ & $.60^{*}$ & - & & & $1.00-5.00$ & .73 \\
4. ETS1 & $.30^{*}$ & $.26^{* *}$ & $.18^{* *}$ & - & & & $1.00-5.00$ & .84 \\
5. ETS2 & $.26^{*}$ & $.42^{*}$ & $.33^{*}$ & $.59^{*}$ & - & & $1.00-5.00$ & .86 \\
6. ETS3 & .15 & $.17^{* *}$ & $.31^{*}$ & $.47^{*}$ & $.59^{*}$ & - & $1.00-5.00$ & .82 \\
\hline
\end{tabular}

EPG $=$ peer-group relationships; ETS $=$ teacher-student relationships; ${ }^{*} p<0.01 ; * * p<0.05$

Table 2. School grade differences

\begin{tabular}{|c|c|c|c|c|}
\hline & \multicolumn{4}{|c|}{ School grade differences } \\
\hline & \multicolumn{2}{|c|}{ Primary $(n=91)$} & \multicolumn{2}{|c|}{ Secondary $(n=79)$} \\
\hline & $\mathrm{M}$ & SD & $\mathrm{M}$ & SD \\
\hline \multicolumn{5}{|l|}{ Sub-scales } \\
\hline EPG1 & 3.85 & .72 & 3.89 & .52 \\
\hline EPG2 & 3.74 & .76 & 3.84 & .53 \\
\hline EPG3 & 3.80 & .74 & 3.76 & .61 \\
\hline ETS1*** & 4.02 & .70 & 3.30 & .62 \\
\hline ETS2 $* *$ & 3.85 & .73 & 3.54 & .63 \\
\hline ETS3 $* * *$ & 3.67 & .74 & 3.20 & .60 \\
\hline
\end{tabular}


Table 3. Changes in experienced emotional engagement in terms of different school grades

\begin{tabular}{ccccccc}
\hline & & \multicolumn{4}{c}{ School grade } \\
\cline { 3 - 4 } & & \multicolumn{2}{c}{ Primary $(\mathrm{n}=84)$} & & \multicolumn{2}{c}{ Secondary $(\mathrm{n}=77)$} \\
\cline { 3 - 4 } \cline { 6 - 7 } & & M diff. & SD diff. & & M diff. & SD diff. \\
\hline EPG & T1-T2 & -.13 & .71 & & -.07 & .46 \\
& T2-T3 & .07 & .61 & & -.08 & .55 \\
& T1-T3 & -.08 & .79 & & $-0.15^{*}$ & .59 \\
ETS & T1-T2 & $-.16^{*}$ & .61 & & $.24^{* *}$ & .65 \\
& T2-T3 & $-.18^{*}$ & .67 & & $-.34^{* *}$ & .61 \\
& T1-T3 & $-.35^{* *}$ & .64 & & -.09 & .85 \\
\hline
\end{tabular}

EPG = peer-group relationships; ETS = teacher-student relationships;

$* t$-test, significant school grade difference $(p<0.05)$

$* *$ t-test, significant school grade difference $(p<0.01)$ 